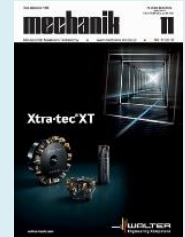

\title{
The influence of the type of a filter on the results of non-contact measurements of the selected free-form surface
}

\author{
Wpływ rodzaju filtru na wyniki bezstykowych pomiarów \\ wybranej powierzchni swobodnej
}

\section{PAWEK TUREK MAREK MAGDZIAK *}

The article concerns the early stages of the reverse engineering of the selected free-form surface. The process of acquisition of measurement data was carried out by using the MCA II coordinate measuring arm equipped with a non-contact measuring probe. The influence of the selected commands and settings of Focus Inspection and CATIA V5-6 software packages in the field of filtration of measurement results on the quality of obtained measurement data was analysed.

KEYWORDS: coordinate measuring technique, free-form surface, digitalization, filtration

Reverse engineering, abbreviated as RE, also known as reconstruction engineering, makes it possible to recreate the geometry of an existing product that does not have technical documentation [1]. Reconstruction engineering includes, e.g. acquisition of measurement data in the form of point clouds [2] and their transformation into a form accepted by computer aided design (CAD) systems [3]. In the case of an object characterized by a complicated geometrical shape, reverse engineering supported by advanced measuring devices is often the only way to obtain a digital equivalent of a given product [4]. Currently, the reverse engineering process is used in many fields, including aviation industry [4] and architecture [5]. Moreover, it is very often used in medicine, for example to reproduce the geometry of internal anatomical structures [6]. The process of reconstruction of objects built of free-form surfaces is possible with the use of modern coordinate measuring systems, that are used during digitization, i.e. at the first stage of reverse engineering [7].

Due to the automation of measurements and the integration of modern coordinate measuring systems with CAD programs, it is possible to recreate the geometry of any product. The accuracy of coordinate measurements of freeform surfaces of products is influenced by many factors, such as: selection of the right measurement strategy [7], choice of computational algorithms [8] and determination of the resolution of acquired measurement data [9]. In addition, the human factor should be taken into account, especially when the coordinate measurements are performed manually. An

\footnotetext{
* Dr inż. Paweł Turek (pturek@prz.edu.pl), dr inż. Marek Magdziak (marekm@prz.edu.pl) - The Faculty of Mechanical Engineering and Aeronautics, Rzeszów University of Technology
}

example of a manual measuring system that can be used in reconstructive engineering is the coordinate measuring arm equipped with both contact and non-contact heads.

An important stage in analyzing the results of non-contact coordinate measurements is the process of their filtration, which can be carried out with various methods. Filtration enables reduction of the excessive amount of measurement data and removal of erroneous points from the cloud, which are unavoidable in the case of non-contact measurements performed in manual mode. However, it is difficult to choose such values of the filtration parameters, which will enable to remove the measurement errors without affecting the quality of the final cloud of the objects to be reconstructed. In the case of measurement data processing, the selection of filters and their settings is usually based on the experience of users of coordinate measuring systems and CAD software.

This article examines the effect of selected types of filters and their settings on the results of measurements of curvilinear surface. The analyzed filters are part of two computer programs commonly used at various stages of the RE process.

\section{Measured product and measuring stand}

The analysis of selected program functions enabling filtration of the point cloud was carried out on the basis of results of non-contact coordinate measurements of the freeform surface of the product (fig. 1a).

The object to be measured was created using 3DP (three dimensional printing) technique. Measurements of the upper surface of this product were made using the measuring system, which was based on the seven-axis measuring arm MCA II, equipped with the non-contact laser probe MMDx100 (fig. 1b).

\section{Methodology of experimental research}

The main goal of the experimental research was to verify the influence of the methods of cloud filtration and their settings on the results of coordinate measurements. For this purpose, the non-contact coordinate measurements of selected curvilinear surface were divided into two main stages. 
a)

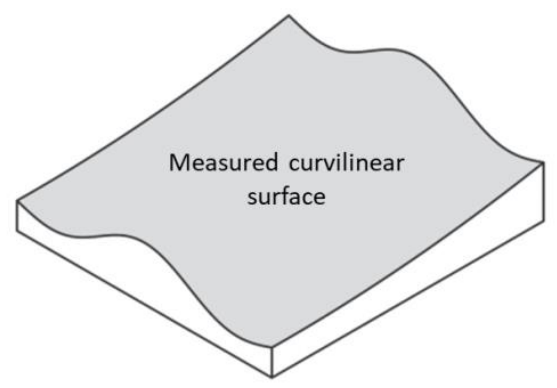

b)

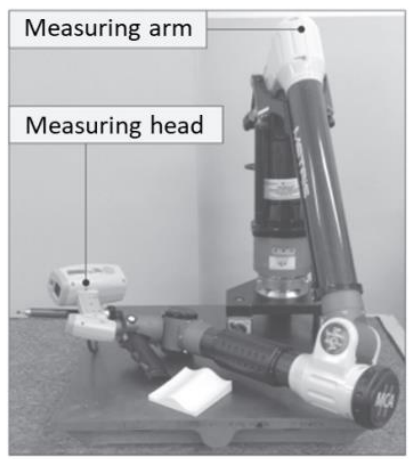

Fig. 1. Measured free-form surface (a) and measuring system (b), by means of which measured data of a curvilinear surface in the form of a point cloud was obtained

At the first stage, the so-called reference grid was obtained. Relative to the reference grid, the influence of different types of filters and values of their parameters on the results of coordinate measurements was tested. Experimental research consisted in comparing point clouds, filtered using four different filters, with a reference grid.

The reference grid was obtained by moving the laser head once along the measured curvilinear surface of the object (fig. 2). The measurement results were saved in STL (stereolithography) format. Conversion of the point cloud of the reference grid to the STL file was carried out using the Focus Handheld measurement program cooperating with the used coordinate measuring system.

The second stage of coordinate measurements consisted in obtaining a cloud of points of considered free-form surface, deliberately containing scanning errors in the form of socalled over-scans.

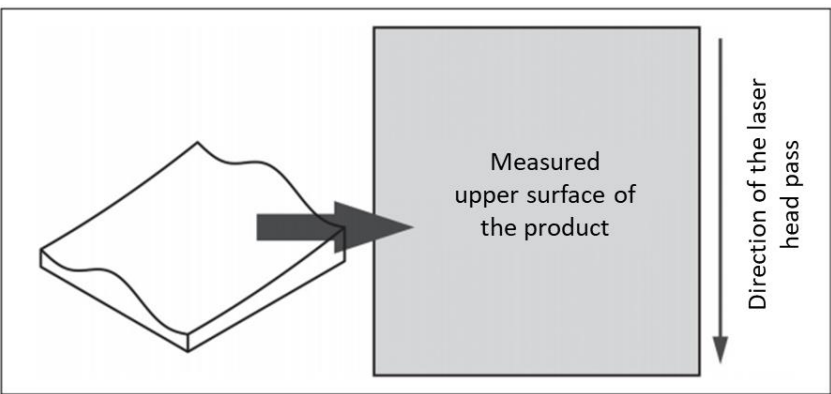

Fig. 2. Measurement strategy used during measurements of the reference grid

Such measurement errors appeared as a result of the triple passage of the laser head in three different directions along the measured free-form surface of the object (fig. 3). Additional coordinate measurements were aimed at simulating errors that may be made by less experienced operators of coordinate measuring arms. Finally, a point cloud was composed of over-scans, which in the further part of the study was subjected to filtration processes using various computer programs. The filtration results were then compared with the reference grid (obtained at the first stage of measurements) to assess the accuracy of the adopted filtration methods.

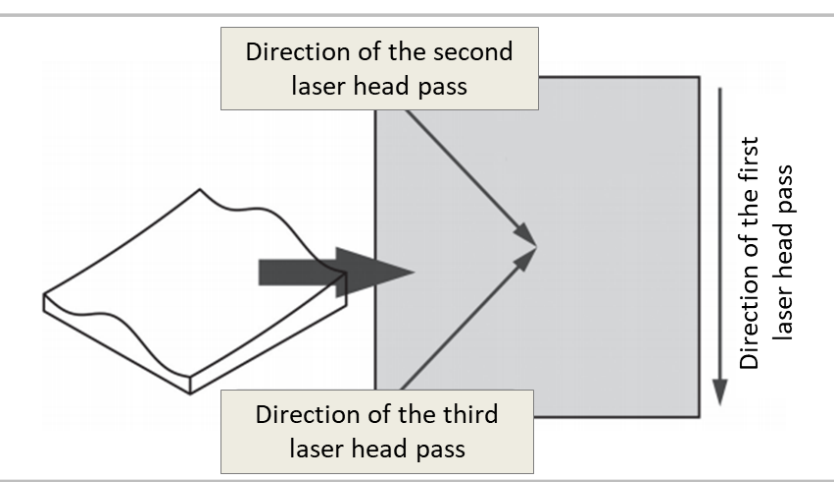

Fig. 3. Measurement strategy used to obtain a point cloud composed of over-scans

Over-scans, typical for non-contact measurements carried out in manual mode, make it difficult to create a 3D model of a product based on a point cloud. In the case of the analyzed object, the mesh created on the basis of the cloud of points containing the over-scans had structural defects and was markedly of inferior quality of the topography in comparison with the reference grid. The disadvantages of the mesh generated from the cloud of points affected by over-scans resulted from overlapping the groups of measurement points located at different levels relative to the reconstructed surface of the product. During the non-contact measurements (both at the first and the second stages of experimental research), the same measurement resolution was used $-0.05 \mathrm{~mm}$.

\section{Compared point cloud filters}

At the next stage, the cloud of points containing overscans was edited. The process consisted of digital filtration of measurement points forming a point cloud, using the Focus Inspection and CATIA V5-6 programs.

The following filters were selected in Focus Inspection software:

- scatter - this filter analyzes the area based on the specified radius of the sphere defined by the user of the measurement software. If this filter is used, the limit number of neighboring measurement points should be taken into account. This parameter specifies the number of points inside the sphere with a given radius, for which they are not removed. In the case of a smaller amount of measurement data, the filtration process is carried out. The applied limit number of points was equal to 2 during experimental tests;

- grid - this filter divides the point cloud into cubes with a user-defined edge length and leaves only one selected point inside each cube, while discarding the remaining measurement data located inside the cube. The smaller the edge length of a specific cube, the largest number of points in a given cloud.

In the case of the CATIA V5-6 program, two filters of the Digitized Shape Editor module were used:

- homogeneous - filter based on a sphere moving between measurement points forming a point cloud. The required parameter is the radius of the sphere, and the removed measurement points are the points located in its center. This filter is similar to the grid filter - the number of points decreases with the increasing radius of the sphere;

- adaptative - the user of this filter must determine the deviation between the points being part of the point cloud and the chords approximating them. In the case of this filter, more points are removed in areas of surface characterized by a low value of curvature. Therefore, this filter is intended primarily for surfaces characterized by a complex geometric shape. 
The filtered point clouds were compared to the reference grid of the considered product using the Deviation Analysis command of the module Digitized Shape Editor, which is available in the CATIA V5-6 software. The results of these analyses are presented in the tabs. I-IV.

TABLE I. Measurement results obtained using a scatter filter
\begin{tabular}{|c|c|c|c|}
\hline $\begin{array}{c}\text { Sphere dia- } \\
\text { meter, mm }\end{array}$ & $\Delta_{\text {avg, }} \mathrm{mm}$ & $\Delta_{\text {max }}, \mathrm{mm}$ & $\sigma, \mathrm{mm}$ \\
\hline 0,1 & 0,0356 & 0,159 & 0,0309 \\
\hline 0,2 & 0,0373 & 0,162 & 0,0283 \\
\hline 0,3 & 0,0466 & 0,214 & 0,0342 \\
\hline 0,4 & 0,0509 & 0,222 & 0,0369 \\
\hline 0,5 & 0,0520 & 0,223 & 0,0375 \\
\hline 0,6 & 0,0523 & 0,223 & 0,0376 \\
\hline 0,7 & 0,0523 & 0,223 & 0,0376 \\
\hline 0,8 & 0,0524 & 0,223 & 0,0376 \\
\hline 0,9 & 0,0524 & 0,223 & 0,0376 \\
\hline 1,0 & 0,0524 & 0,223 & 0,0376 \\
\hline Range & 0,0168 & 0,064 & 0,0093 \\
\hline
\end{tabular}

TABLE II. Measurement results obtained using a grid filter

\begin{tabular}{|c|c|c|c|}
\hline $\begin{array}{c}\text { Cube edge length, } \\
\mathrm{mm}\end{array}$ & $\Delta_{\text {avg }}, \mathrm{mm}$ & $\Delta_{\max }, \mathrm{mm}$ & $\sigma, \mathrm{mm}$ \\
\hline 0,1 & 0,0525 & 0,223 & 0,0376 \\
\hline 0,2 & 0,0529 & 0,223 & 0,0378 \\
\hline 0,3 & 0,0533 & 0,223 & 0,0380 \\
\hline 0,4 & 0,0537 & 0,223 & 0,0381 \\
\hline 0,5 & 0,0540 & 0,223 & 0,0382 \\
\hline 0,6 & 0,0551 & 0,223 & 0,0387 \\
\hline 0,7 & 0,0558 & 0,223 & 0,0387 \\
\hline 0,8 & 0,0565 & 0,214 & 0,0388 \\
\hline 0,9 & 0,0571 & 0,209 & 0,0390 \\
\hline 1,0 & 0,0576 & 0,205 & 0,0392 \\
\hline Range & 0,0051 & 0,018 & 0,0016 \\
\hline
\end{tabular}

TABLE III. Measurement results obtained using a homogeneous filter

\begin{tabular}{|c|c|c|c|}
\hline $\begin{array}{c}\text { Sphere radius, } \\
\mathrm{mm}\end{array}$ & $\Delta_{\text {avg, }} \mathrm{mm}$ & $\Delta_{\max }, \mathrm{mm}$ & $\sigma, \mathrm{mm}$ \\
\hline 0,2 & 0,0564 & 0,223 & 0,0385 \\
\hline 0,6 & 0,0622 & 0,222 & 0,0387 \\
\hline 1,0 & 0,0627 & 0,222 & 0,0381 \\
\hline 1,4 & 0,0638 & 0,198 & 0,0380 \\
\hline 1,8 & 0,0640 & 0,198 & 0,0385 \\
\hline 2,2 & 0,0641 & 0,189 & 0,0392 \\
\hline 2,6 & 0,0655 & 0,189 & 0,0390 \\
\hline 3,0 & 0,0644 & 0,178 & 0,0382 \\
\hline 3,4 & 0,0643 & 0,160 & 0,0388 \\
\hline 3,8 & 0,0641 & 0,174 & 0,0398 \\
\hline Range & 0,0091 & 0,063 & 0,0012 \\
\hline
\end{tabular}

The tables contain:

- arithmetic means $\left(\Delta_{\text {avg }}\right)$ of deviations and maximum $\left(\Delta_{\max }\right)$ deviations of point clouds, calculated relative to the reference grid;

- values of standard deviations $(\sigma)$;

- values of individual parameters characteristic for compared filters.

On the basis of the obtained results, the ranges were calculated.
TABLE IV. Measurement results obtained using an adaptative filter

\begin{tabular}{|c|c|c|c|}
\hline $\begin{array}{c}\text { Deviation from the } \\
\text { chord, } \mathrm{mm}\end{array}$ & $\Delta_{\text {avg, }} \mathrm{mm}$ & $\Delta_{\max }, \mathrm{mm}$ & $\sigma, \mathrm{mm}$ \\
\hline 0,12 & 0,0679 & 0,223 & 0,0437 \\
\hline 0,14 & 0,0651 & 0,223 & 0,0437 \\
\hline 0,16 & 0,0547 & 0,206 & 0,0406 \\
\hline 0,18 & 0,0474 & 0,172 & 0,0352 \\
\hline 0,20 & 0,0453 & 0,160 & 0,0333 \\
\hline 0,22 & 0,0444 & 0,145 & 0,0326 \\
\hline 0,24 & 0,0449 & 0,145 & 0,0328 \\
\hline 0,26 & 0,0443 & 0,144 & 0,0326 \\
\hline 0,28 & 0,0459 & 0,153 & 0,0332 \\
\hline 0,30 & 0,0462 & 0,153 & 0,0336 \\
\hline Range & 0,0236 & 0,079 & 0,0111 \\
\hline & & & \\
\hline
\end{tabular}

\section{Conclusions}

The results of the conducted research indicate a significant influence of the adopted type of the point cloud filter on the results of coordinate measurements of the curvilinear surface. In addition, regardless of the applied filter, significant fluctuations in the measurement results were observed for the adopted various values of filtration parameters. The largest ranges were noted when using scatter and adaptative filters.

Therefore, in order to obtain point clouds correctly representing the reconstructed objects, it is advisable to test various filtration methods and their parameters before the final selection of settings in the scope of data editing.

\section{REFERENCES}

1. Raja V., Fernandes K.J. "Reverse engineering - an industrial perspective". Springer, 2010.

2. Bubicz M. „Szybkie prototypowanie. Cz. II. Skanery 3D. Wstęp do inżynierii odwrotnej". Projektowanie i Konstrukcje Inżynierskie. 6, 9 (2008): pp. 12-21.

3. Wyleżoł M. „Inżynieria odwrotna w doskonaleniu konstrukcji”. Modelowanie Inżynierskie. 1, 32 (2006): pp. 485-490.

4. Burek J., Żurek P., Gdula M., Misiura J., Żurawski K. „Wykonanie pióra łopatki na podstawie modelu uzyskanego w wyniku pomiarów współrzędnościowych". Mechanik. 2 (2015): CD.

5. Gibson I., Kvan T., Ming L.W. "Rapid prototyping for architectural models". Rapid Prototyping Journal. 8, 2 (2002): pp. 91-95.

6. Ciocca L., Mazzoni S., Fantini M., Persiani F., Baldissara P., Marchetti C., Scotti R. "A CAD/CAM-prototyped anatomical condylar prosthesis connected to a custom-made bone plate to support a fibula free flap". Medical \& Biological Engineering \& Computing. 50, 7 (2012): pp. 743-749.

7. Barbero B.R., Ureta E.S. "Comparative study of different digitization techniques and their accuracy". Computer-Aided Design. 43, 2 (2011): pp. 188-206.

8. Magdziak M., Wdowik R. "Comparison of selected methods of probe radius correction based on measurements of ceramic workpieces". Procedia CIRP. 62 (2017): pp. 391-395.

Translation of scientific articles, their computer composition and publishing them on the website www.mechanik.media.pl by original articles in Polish is a task financed from the funds of the Ministry of Science and Higher Education designated for dissemination of science.

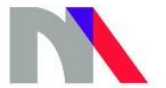

Ministry of Science and Higher Education Republic of Poland 